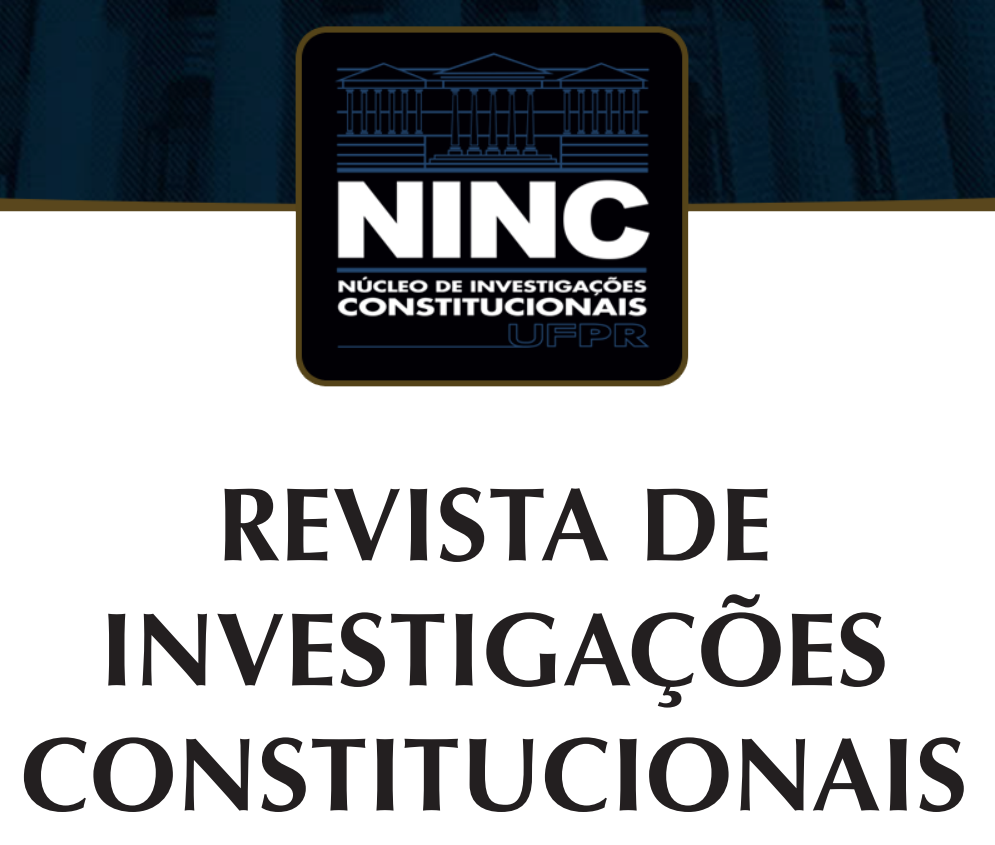

JOURNAL OF CONSTITUTIONAL RESEARCH

vol. 7 | n. 1 | janeiro/abril 2020 | ISSN 2359-5639 | Periodicidade quadrimestral Curitiba | Núcleo de Investigações Constitucionais da UFPR | www.ninc.com.br 


\title{
¿Una paradoja interamericana? Chile, un Estado que cumple las sentencias del Sistema Interamericano de Derechos Humanos, pero que impulsa su reforma
}

\section{An Inter-American Paradox? Chile, a State that Complies with the Inter-American System of Human Rights Judgments, but that Presses for its Reform}

\author{
ÁLVARO PAÚL l,* \\ 'Pontifícia Universidad Católica de Chile (Santiago, Chile) \\ alvaro.paul@uc.cl \\ http://orcid.org/0000-0003-3882-450X \\ Recebido/Received: 17.11.2019 / November $17^{\text {th }}, 2019$ \\ Aprovado/Approved: 12.02 .2020 / February $12^{\text {th }}, 2020$
}

Resumen

A muchos les puede parecer paradojal que Chile, un Estado bastante cumplidor de las sentencias de la Corte Interamericana, esté liderando una declaración de los Estados de Argentina, Brasil, Chile, Colombia y Paraguay, en la que hacen notar problemas del sistema interamericano de derechos humanos. Les puede parecer paradojal, si piensan que las sugerencias de reformas buscarán necesariamente debilitar el sistema interamericano. ¿Es posible que un Estado critique al sistema interamericano de derechos humanos sin que busque debilitarlo? Este trabajo, en primer lugar, confirma la percepción de que Chile es un Estado que cumple con las sentencias de la Corte. Luego, analiza las observaciones de la Declaración, para concluir que cada una de ellas es atendible, por lo

\section{Abstract}

To many people it may seem paradoxical that Chile, a State that is very much abiding with the Inter-American Court's decisions, is leading a declaration of the States of Argentina, Brazil, Chile, Colombia and Paraguay, were they express some problems of the Inter-American System of Human Rights. These people may find it paradoxical, if they think that suggestions for reform will necessarily aim at weakening the System. Is it possible for a State to criticize the Inter-American human rights system without trying to weaken it? This article, in the first place, confirms the perception that Chile is a State that fulfils the Inter-American Court's judgments. Then, it analyses each of the suggestions of the Declaration, in order to conclude that they are reasonable, so that it is not a paradox for a State that is committed to the

Como citar esse artigo/How to cite this article: PAÚL, Álvaro. ¿Una Paradoja Interamericana? Chile, un Estado que cumple las Sentencias del Sistema Interamericano de Derechos Humanos, pero que Impulsa su Reforma. Revista de Investigações Constitucionais, Curitiba, vol. 7, n. 1, p. 59-85, jan./abr. 2020. DOI: 10.5380/rinc.v7i1.70231

* Profesor Asociado de la Pontificia Universidad Católica de Chile (Santiago, Chile). Doctor en Derecho por Trinity College Dublin, Master en Derecho (MJur) por la Universidad de Oxford, y Graduado de la Universidad de los Andes (Chile). Ha sido pasante o visitante de estudios en la Corte Interamericana de DD.HH., la Comisión Interamericana de DD.HH. y el Tribunal Europeo de DD.HH. E-mail: alvaro.paul@uc.cl. 
que no es una paradoja que un Estado comprometido con el Sistema las plantee, sino que, por el contrario, muestra su compromiso con el Sistema.

Palabras-chave: Sistema Interamericano de Derechos Humanos; cumplimiento; declaración de Estados; fortalecimiento.
System, to make them. On the contrary, it shows its commitment to the System.

Keywords: Inter-American System of Human Rights, compliance, States declaration, strengthening.

\section{SUMARIO}

1. Introducción; 2. Chile y el Sistema Interamericano de Derechos Humanos; 2.1. Sentencias de la Corte Interamericana que involucran al Estado de Chile; 2.2. Cumplimiento de sentencias por parte del Estado de Chile; 2.3. Ordenamiento jurídico chileno y cumplimiento de las sentencias de la Corte; 2.4. Control de convencionalidad y ordenamiento jurídico chileno; 3. Declaración liderada por Chile sobre Mejoras al Sistema Interamericano; 3.1. Cuestiones generales; 3.2. Consideración de cada una de las cinco propuestas; 3.2.1. Principio de subsidiariedad; 3.2.2. Legítima autonomía; 3.2.3. Atraso procesal y garantías; 3.2.4. Derechos y su aplicación; 3.2.5. Reparaciones; 4. Conclusiones; 5. Referencias.

\section{INTRODUCCIÓN}

¿Es posible que un Estado critique al sistema interamericano de derechos humanos sin que busque debilitarlo? Esta pregunta es razonable, a la luz de algunos procedimientos de "fortalecimiento" que algunos Estados poco comprometidos con el Sistema Interamericano han planteado, por ejemplo, en los años noventa, o más recientemente, en $2011^{1}$. Dicha interrogante es también fundamental para interpretar adecuadamente la declaración que los Estados de Argentina, Brasil, Chile, Colombia y Paraguay presentaron el 11 de abril de 2019 al Secretario Ejecutivo de la Comisión Interamericana de Derechos Humanos (CIDH) ${ }^{2}$, en la que plantean ciertas inquietudes que les genera el actuar de los órganos del Sistema Interamericano. Esta declaración presenta reparos tanto a la CIDH como a la Corte Interamericana de Derechos Humanos (Corte IDH).

La Declaración generó mucho revuelo en el ámbito interamericano, tanto por parte de la academia como de los litigantes. La CIDH reaccionó ponderadamente frente a la Declaración, pues fijó su posición en los siguientes términos:

La CIDH ha recibido una Declaración suscrita por Chile, Argentina, Brasil, Colombia y Paraguay que señala la importancia del [Sistema Interamericano de Derechos Humanos] y

\footnotetext{
NIKKEN, Pedro. El Sedicente 'Fortalecimiento' del Sistema Interamericano de Derechos Humanos y sus Dobles Estándares Frente a las Obligaciones Internacionales de los Estados Americanos. Revista Instituto Interamericano de Derechos Humanos, vol. 56, p. 76-80, jul.-dic.2012.

2 GOBIERNO NACIONAL DE PARAGUAY. Gobiernos de Argentina, Brasil, Chile, Colombia y Paraguay se Manifiestan sobre el Sistema Interamericano de Derechos Humanos. Gobierno Nacional de Paraguay, Asunción, Abr. 24, 2019. Disponible en <https://www.mre.gov.py/index.php/noticias-de-embajadas-y-consulados/gobiernos-de-argentina-brasil-chile-colombia-y-paraguay-se-manifiestan-sobre-el-sistema-interamericano-de-derechos-humanos>. Acceso en: 6 ago. 2019.
} 
hace sugerencias para mejorar su eficacia. La CIDH valora la postura constructiva de los Estados y examinará el tema durante sus próximas Sesiones. ${ }^{3}$

En cambio, otros actores no tuvieron la misma disposición frente a esta declaración. En efecto, un grupo importante de académicos redactaron un posicionamiento que critica profusamente la Declaración ${ }^{4}$, y organizaciones no gubernamentales como Human Rights Watch y Amnistía Internacional atacaron la iniciativa de tales cinco Estados ${ }^{5}$.

Para resolver la interrogante de si es posible que un Estado critique al Sistema sin buscar debilitarlo, analizaremos el caso práctico de Chile. No nos centraremos en este Estado porque el autor de este trabajo es chileno, sino porque, según indica la prensa, dicho Estado sería el promotor de la declaración de los cinco Estados ${ }^{6}$. Observaremos la actitud del Estado de Chile ante el Sistema Interamericano, analizaremos si tiene altas tasas de cumplimiento de las sentencias de la Corte IDH, pues ello denotaría un compromiso con el Sistema, lo que sería un indicio de que no busca debilitarlo. En segundo lugar, luego de demostrar que Chile se encuentra dentro de los Estados que más cumplen con las sentencias de la Corte, analizaremos cada una de las peticiones de la declaración de los cinco Estados, para poder juzgar en su mérito si ellas son o no razonables, y así determinar si Chile estaría encabezando una cruzada en contra del Sistema Interamericano, o si sus críticas constituyen ideas para una reforma que perfeccione el Sistema.

\footnotetext{
3 La CIDH no emitió ningún comunicado de prensa oficial, pero se pronunció en Twitter sobre este documento: COMISIÓN INTERAMERICANA DE DERECHOS HUMANOS (@CIDH). La CIDH ha recibido una Declaración suscrita por Chile, Argentina, Brasil, Colombia y Paraguay que señala la importancia del SIDH y hace sugerencias para mejorar su eficacia. La CIDH valora la postura constructiva de los Estados y examinará el tema durante sus próximas Sesiones. Twitter, Abr. 23, 2019. Disponible en: <https://twitter.com/cidh/status/1120750186219868162?lang=en>. Acceso en: 6 ago. 2019. Llama la atención que la Comisión reaccionara a esta declaración sólo mediante un comentario en la red social Twitter, en lugar de elaborar un comunicado de prensa formal.
}

4 MADRAZO LAJOUS, Alejandro et al. Posicionamiento frente a la Declaración sobre el Sistema Interamericano de Derechos Humanos, Ciudad de México, May. 9, 2019. Disponible en <https://ibero.mx/files/2019/posicionamiento_cidh_ibero_osidh.pdf>. Acceso en: 6 ago. 2019.

5 MASERI, Sergio Gómez. HRW denuncia ataque de Colombia y otros países contra la CIDH. El Tiempo, Washington, Abr. 24. Disponible en <https://www.eltiempo.com/mundo/eeuu-y-canada/denuncian-ataque-de-colombia-y-otros-paises-contra-la-cidh-353034>. Acceso en: 6 ago. 2019; TUCKER, Duncan. Américas. Sistema Interamericano constituye una garantía fundamental para la vigencia de los derechos humanos en la región. Amnistía Internacional, Abr. 24. Disponible en <https://www.amnesty.org/es/latest/news/2019/04/americas-sistema-interamericano-fundamental-para-derechos-humanos/>. Acceso en: 17 sep. 2019.

6 COOPERATIVA.CL. Prensa argentina: Piñera pidió a Macri apoyar sus críticas a la CIDH. Cooperativa.CL, Abr. 24. Disponible en <https://www.cooperativa.cl/noticias/pais/relaciones-exteriores/prensa-argentina-pinera-pidio-a-macri-apoyar-sus-criticas-a-la-cidh/2019-04-24/193120.htm>. Acceso en: 6 ago. 2019; COOPERATIVA. CL. Human Rights Watch: Gobierno de Piñera impulsó críticas internacionales a CIDH. Cooperativa.CL, Abr. 25. Disponible en <https://www.cooperativa.cl/noticias/pais/relaciones-exteriores/human-rights-watch-gobierno-de-pinera-impulso-criticas-internacionales/2019-04-25/084313.html>. Acceso en: 6 ago. 2019. 
Hay un tema relevante que no puede ser ignorado por este artículo: los actuales gobiernos de todos los Estados autores de la Declaración son de una tendencia política de centroderecha. Nos parece que esta posición política no tiene mayor relevancia al tratar de desentrañar las intenciones favorables o desfavorables de la Declaración hacia el Sistema. En efecto, los gobiernos de uno u otro sector del espectro político pueden tener tanto buenas como malas intenciones frente al Sistema interamericano. Por lo demás, el anterior gobierno del actual Presidente de Chile, Sebastián Piñera, mantuvo la actitud de compromiso con el Sistema Interamericano que tuvieron los gobiernos que lo precedieron. Así, la tendencia política del impulsor de la medida no nos parece significativa para los efectos de responder la pregunta planteada más arriba. Sólo sería relevante para explicar por qué el Estado impulsor de la Declaración buscó apoyo entre los gobiernos de los demás Estados firmantes. Por lo anterior, este artículo no dará mayor tratamiento a este asunto político.

\section{CHILE Y EL SISTEMA INTERAMERICANO DE DERECHOS HUMA- NOS}

\subsection{Sentencias de la Corte Interamericana que involucran al Estado de Chile}

Si se hiciera un ranking de los Estados que más han sido sometidos a Corte Interamericana de Derechos Humanos, Chile se encontraría, junto con México, en el séptimo lugar de entre los 20 Estados que están actualmente sometidos a la jurisdicción de la Corte IDH ${ }^{7}$. En otras palabras, en atención a esta variable, Chile es un Estado promedio, inclinado levemente hacia los Estados que más causas han enfrentado ante la Corte IDH. Desde 1990, año en que Chile se sometió a la jurisdicción de la Corte, ésta ha fallado diez casos en su contra. Varios de los casos que han afectado a este Estado han sido emblemáticos y de gran importancia para el devenir del Sistema. Así, por ejemplo, el primer caso contra Chile, el de La Última Tentación de Cristo, le sirvió a la Corte para referirse a la libertad de expresión ${ }^{8}$, poniendo un paréntesis a los casos sobre el derecho a la vida y la prohibición de la tortura; en el caso Almonacid Arellano, la Corte creó la doctrina del control de convencionalidad ${ }^{9}$, y con el caso Atala Riffo, la Corte entró

\footnotetext{
7 CORTE INTERAMERICANA DE DERECHOS HUMANOS. Informe Anual 2018, p. 86, 2019. Disponible en <http://www.corteidh.or.cr/tablas/informe2018/espanol.pdf>. Acceso en: 06 ago. 2019.

8 CORTE INTERAMERICANA DE DERECHOS HUMANOS. Caso OImedo Bustos y Otros vs. Chile (La Última Tentación de Cristo), Fondo, Reparaciones y Costas, Serie $C n^{\circ} 73$. Publicado en 5 feb. 2001.

9 CORTE INTERAMERICANA DE DERECHOS HUMANOS. Caso Almonacid Arellano y Otros vs. Chile, Excepciones Preliminares, Fondo, Reparaciones y Costas, Serie $C n^{\circ} 154$, párr. 124. Publicado en 26 sep. 2006.
} 
de lleno en el tema de la orientación sexual, una materia que genera una importante división entre la población americana ${ }^{10}$.

En estos diez casos, la Corte IDH ha ordenado reparaciones que parecen ser particularmente complejas. Así, por dar solo algunos ejemplos, la Corte ha obligado a Chile a: modificar su Constitución Política ${ }^{11}$, reformar su legislación sobre procedimientos penales militares ${ }^{12}$, asegurarse de que la Ley de Amnistía dictada en la última dictadura no siguiera surtiendo efectos ${ }^{13}$, revisar o anular condenas dictadas por Consejos de Guerra al comienzo del Régimen Militar ${ }^{14}$, dejar sin efecto sentencias dictadas por su Corte Suprema en plena democracia ${ }^{15}$, y pagar algunas de las mayores sumas individuales ordenadas por la Corte IDH como indemnizaciones de perjuicios ${ }^{16}$.

\subsection{Cumplimiento de sentencias por parte del Estado de Chile}

El Estado de Chile ha cumplido de muy buen grado ciertas reparaciones exigidas por la Corte IDH, pues algunas de ellas eran claramente necesarias y tendrían un efecto altamente valorado en el país ${ }^{17}$. Por ejemplo, la sentencia del caso Claude Reyes exigió establecer un sistema completo de transparencia de los documentos que están

10 CORTE INTERAMERICANA DE DERECHOS HUMANOS. Caso Atala Riffo e Hijas vs. Chile, Fondo, Reparaciones y Costas, Serie $C n^{\circ} 239$. Publicado en 24 feb. 2001.

11 CORTE INTERAMERICANA DE DERECHOS HUMANOS. Caso OImedo Bustos y Otros vs. Chile (La Última Tentación de Cristo), Fondo, Reparaciones y Costas, Serie $C n^{\circ} 73$, párrs. 98, en relación con el párr. 45.c y 52. Publicado en 5 feb. 2001.

12 CORTE INTERAMERICANA DE DERECHOS HUMANOS. Caso Palamara Iribarne vs. Chile, Fondo, Reparaciones y Costas, Serie $C \mathrm{n}^{\circ} 135$, párr. 256 y 257. Publicado en 22 nov. 2005.

13 CORTE INTERAMERICANA DE DERECHOS HUMANOS. Caso Almonacid Arellano y Otros vs. Chile, Excepciones Preliminares, Fondo, Reparaciones y Costas, Serie C n 154, párr. 145. Publicado en 26 sep. 2006.

14 CORTE INTERAMERICANA DE DERECHOS HUMANOS. Caso Humberto Maldonado Vargas y otros vs. Chile, Fondo, Reparaciones y Costas, Serie $C n^{\circ}$ 300, párr. 167. Publicado en 2 sept. 2015.

15 CORTE INTERAMERICANA DE DERECHOS HUMANOS. Caso Norín Catrimán y Otros (Dirigentes, Miembros y Activista del Pueblo Indígena Mapuche) vs. Chile, Fondo, Reparaciones y Costas, Serie $\mathrm{C}^{\circ} 279$, párr. $^{\circ}$ 422. Publicado en 29 may. 2014.

16 CORTE INTERAMERICANA DE DERECHOS HUMANOS. Caso Órdenes Guerra y Otros vs. Chile, Fondo, Reparaciones y Costas, Serie C n³72, párr. 124. Publicado en 29 nov. 2018.

17 Ellas no son necesariamente las más bulladas, pues éstas no siempre han tenido una gran influencia en el modo como se hacen las cosas al interior del Estado, por ejemplo, en el caso Almonacid Arellano la Corte ordenó dejar sin efecto la ley de amnistía chilena, pero los tribunales ya habían dejado de aplicar esta norma (a pesar de que ella sigue vigente en el país) (CORTE INTERAMERICANA DE DERECHOS HUMANOS. Caso Almonacid Arellano y Otros vs. Chile, Excepciones Preliminares, Fondo, Reparaciones y Costas, Serie C n 154, párr. 142.a. Publicado en 26 sep. 2006). Algo similar ocurre con la orden de no permitir que prescriban las indemnizaciones civiles solicitadas como consecuencia de las violaciones cometidas durante la reciente dictadura, pues ello ya había sido ordenado por nuestra Corte Suprema (CORTE INTERAMERICANA DE DERECHOS HUMANOS. Caso Órdenes Guerra y Otros vs. Chile, Fondo, Reparaciones y Costas, Serie C n³72, párrs. 114 y 121 . Publicado en 29 nov. 2018). En gran medida, este desajuste entre lo ordenado por la Corte IDH y lo que ocurre en la realidad nacional se debe al largo tiempo que transcurre entre que ocurren los hechos y que un caso es resuelto por la Corte IDH. 
en poder del Estado ${ }^{18}$. Este caso hizo que se creara el Consejo para la Transparencia, generando un cambio radical en el modo como se aproxima el Estado a la información y a los derechos de los ciudadanos en esta materia.

A diferencia de lo que ocurre en Estados como Perú y Costa Rica ${ }^{19}$, Chile carece de un sistema reglamentado para dar cumplimiento a las sentencias de la Corte IDH, incluso en materia de reparaciones pecuniarias. No obstante ello, y que la Corte IDH ha ordenado reparaciones que exigen acciones bastante radicales, Chile es un Estado que presenta tasas elevadas de cumplimiento de las sentencias de la Corte IDH. Esto puede observarse en las resoluciones de supervisión de cumplimiento de las sentencias de dicha Corte. Tales resoluciones son bastante irregulares, en el sentido de que la Corte IDH no cuenta con un patrón que explique por qué supervisa unas sentencias y no otras ${ }^{20}$, pero no obstante ello, nos permiten hacernos una idea del grado de cumplimiento por parte de los Estados en general, y de Chile en particular.

Para su informe anual de 2018, la Corte IDH elaboró un gráfico que muestra el total de casos fallados en contra de cada Estado, separando los casos con supervisión de cumplimiento abierta y los que la Corte declaró que cumplen con las reparaciones ordenadas ${ }^{21}$. Este gráfico nos permite observar que en términos generales, de entre los 239 casos que la Corte declara haber fallado en contra de los Estados hasta 2018, 31 se habrían cumplido, y 208 se encontrarían con una supervisión de cumplimiento abierta, es decir, no tienen cumplimiento total ${ }^{22}$. Esto nos muestra que sólo 17,5\% de los casos de la Corte IDH han sido plenamente cumplidos.

En el referido gráfico podemos observar que hasta 2018 se habían fallado 10 casos en contra de Chile, de los cuales 8 estaban con supervisión de cumplimiento abierta, y 2 se han declarado ya cumplidos ${ }^{23}$ (los casos La Última Tentación de Cristo y

\footnotetext{
18 CORTE INTERAMERICANA DE DERECHOS HUMANOS. Caso Claude Reyes y Otros vs. Chile, Fondo, Reparaciones y Costas, Serie C n 151, párrs. 162 y 163. Publicado en 19 sep. 2006.

19 Perú cuenta con la Ley $n^{\circ} 27.775$, Ley que Regula el Procedimiento de Ejecución de Sentencias Emitidas por Tribunales Supranacionales, y Costa Rica cuenta con la Ley $n^{\circ} 6889$, Convenio para la Sede de la Corte Interamericana de Derechos Humanos, que en su artículo 27 establece que las resoluciones de la Corte que sean debidamente comunicadas "tendrán la misma fuerza ejecutiva y ejecutoria que las dictadas por los tribunales costarricenses."

20 Véase HAWKINS, Darren; JACOBI, Wade. Partial Compliance: A Comparison of the European and Inter-American Courts for Human Rights. Journal of International Law and International Relations, vol. 6, n. 1, 2010, p. 48.

21 CORTE INTERAMERICANA DE DERECHOS HUMANOS. Informe Anual 2018, p. 86, 2019. Disponible en <http://www.corteidh.or.cr/tablas/informe2018/espanol.pdf>. Acceso en: 06 ago. 2019.

22 Ellos incluyen los 14 casos a los que la Corte aplicó el artículo 65 de la Convención Americana sobre Derechos Humanos (CORTE INTERAMERICANA DE DERECHOS HUMANOS. Informe Anual 2018, p. 85-86, 2019. Disponible en <http://www.corteidh.or.cr/tablas/informe2018/espanol.pdf>. Acceso en: 06 ago. 2019).

23 CORTE INTERAMERICANA DE DERECHOS HUMANOS. Informe Anual 2018, p. 86, 2019. Disponible en <http:// www.corteidh.or.cr/tablas/informe2018/espanol.pdf>. Acceso en: 06 ago. 2019.
} 
Claude Reyes ${ }^{24}$ ). De ese modo, un $20 \%$ de los casos dictados contra Chile cuenta con un cumplimiento total. Así, Chile comparte con Panamá el séptimo lugar de entre los Estados según su porcentaje de casos con cumplimiento total. Estos Estados son superados por Ecuador y Nicaragua (40\%), Bolivia y Surinam (30\%), Argentina (27\%) y Costa Rica (25\%). Estos datos situarían a Chile como un Estado medio en cuanto a su cumplimiento de las sentencias de la Corte, pues estaría sólo un poco por sobre el promedio de cumplimiento de las sentencias de la Corte IDH (17,5\%). Los datos anteriores, sin embargo, se prestan para equívocos, puesto que si analizamos caso a caso, notaremos que el grado de cumplimiento de Chile es mucho mayor. Tanto es así, que se podría considerar que Chile es uno de los Estados que más cumplen con las sentencias de la Corte. Esto se puede concluir en atención a lo siguiente:

a) Dos de las diez sentencias dictadas contra Chile son del año $2018^{25}$, y el grado de dificultad de las reparaciones que ordena la Corte IDH suele hacer imposible cumplirlas en un plazo breve (de hecho, la Corte estila ordenar a las partes que hagan un primer informe del cumplimiento recién un año después de notificada la sentencia). Por eso, cualquier análisis que se haga en este momento sobre si Chile cumple con las sentencias de la Corte debiera considerar un universo de sólo ocho sentencias. Calculado así, el porcentaje de cumplimiento de este Estado sería de un 25\% (dos casos, de un total de ocho).

b) Por otro lado, hay dos sentencias que en sus últimas supervisiones de cumplimiento (abril de 2015 y febrero de 2017) estaban casi completamente cumplidas, faltando sólo un par de cosas menores. Se trata de las sentencias de los casos Atala Riffo y García Lucero. Respecto del primer caso, sólo se ha pedido seguir implementando programas de formación y capacitación ${ }^{26}$, y respecto del segundo, se pide continuar investigando el asunto a nivel nacional ${ }^{27}$. En atención a que faltaba sólo dar cumplimiento a estas medidas, y al hecho de que ha transcurrido un tiempo razonable desde su última revisión, es posible suponer que habría mérito para dar por cumplidas estas sentencias (faltando sólo que se les haga una nueva supervisión de cumplimiento para constatar esta realidad). De este modo, puede decirse que Chile habría dado

24 CORTE INTERAMERICANA DE DERECHOS HUMANOS. Véanse Olmedo Bustos y Otros vs. Chile (La Última Tentación de Cristo), Supervisión de Cumplimiento. Publicado en 28 nov. 2003. y CORTE INTERAMERICANA DE DERECHOS HUMANOS. Caso Claude Reyes y Otros vs. Chile, Supervisión de Cumplimiento. Publicado en 24 nov. 2008.

25 CORTE INTERAMERICANA DE DERECHOS HUMANOS. Caso Poblete Vilches y Otros vs. Chile, Fondo, Reparaciones y Costas, Serie $C n^{\circ}$ 349. Publicado en 8 mar. 2018. y CORTE INTERAMERICANA DE DERECHOS HUMANOS. Caso Órdenes Guerra y Otros vs. Chile, Fondo, Reparaciones y Costas, Serie $\mathrm{C} \mathrm{n}^{\circ} 372$. Publicado en 29 nov. 2018

26 CORTE INTERAMERICANA DE DERECHOS HUMANOS. Caso Atala Riffo e Hijas vs. Chile, Supervisión de Cumplimiento, párr. "Resuelve" $n^{\circ}$ 2. Publicado en 10 feb. 2017.

27 CORTE INTERAMERICANA DE DERECHOS HUMANOS. García Lucero y otras vs. Chile, Supervisión de Cumplimiento, párr. "Resuelve" n². Publicado en 17 abr. 2015. 
cumplimiento, o estaría próximo a dar cumplimiento, a cuatro de las ocho causas respecto de las cuales ha transcurrido un plazo adecuado (según lo que se planteó en la letra a). Con ello, estaríamos hablando de un 50\% de cumplimiento.

El antedicho porcentaje de cumplimiento es muy superior al 17\% de los casos totalmente cumplidos en el sistema interamericano, y supera incluso el $40 \%$ de los Estados que más han cumplido con las sentencias de la Corte según el Informe Anual 2018. No obstante ello, no podríamos afirmar que Chile sea el Estado que más cumple con las sentencias de la Corte IDH, pues otros Estados podrían estar en situaciones similares a las recién descritas. Para hacer una afirmación de esa naturaleza habría que analizar el cumplimiento de cada caso en particular. En cambio, habiendo revisado someramente la situación de otros Estados (por ejemplo, si también fueron condenados por la Corte el año 2018), es posible afirmar que Chile se encontraría dentro de los Estados que más cumplen.

Por último, no está de más hacer presente que las reparaciones que Chile tiene pendientes son, en general, reparaciones estructurales, como la reforma de legislación. En efecto, las medidas más sencillas, como las disculpas públicas y el pago de indemnizaciones, suelen ser prontamente cumplidas. Esto no debe ser pasado por alto, pues el cumplimiento de estas medidas sencillas también sirve para mostrar el compromiso que tiene un Estado con las reparaciones ordenadas por la Corte IDH.

\subsection{Ordenamiento jurídico chileno y cumplimiento de las sentencias de la Corte}

Como decíamos, en Chile no existe legislación que disponga cómo llevar adelante el cumplimiento de las sentencias de la Corte IDH. No existe un procedimiento, ni siquiera, en materia de indemnizaciones, lo que resulta curioso si se observa que las indemnizaciones son el tipo de reparación más cumplido por Chile (y por los demás Estados) ${ }^{28}$. Posiblemente, lo más difícil de cumplir, lo que más obliga a mantener los casos bajo supervisión del sistema interamericano son las modificaciones legales y las decisiones relativas a dejar sin efecto sentencias ${ }^{29}$.

Respecto de estas últimas, el año 2019 se observó una modificación en el criterio de la Corte Suprema de Chile, que generó bastante revuelo al interior de la comunidad jurídica local. Esto ocurrió en relación con el caso Norín Catrimán (Lonkos y Otros Comuneros Mapuches), en el que la Corte IDH ordenó que el Estado de Chile dejara sin efecto ciertas penas penales y civiles, así como sus consecuencias y registros, a la mayor

28 HAWKINS, Darren; JACOBI, Wade. Partial Compliance: A Comparison of the European and Inter-American Courts for Human Rights. Journal of International Law and International Relations, vol. 6, n. 1, 2010, p. 57.

29 HAWKINS, Darren; JACOBI, Wade. Partial Compliance: A Comparison of the European and Inter-American Courts for Human Rights. Journal of International Law and International Relations, vol. 6, n. 1, 2010, p. 5758. 
brevedad posible30. Frente a esto, y luego de una solicitud del Ejecutivo, la Corte Suprema llamó a una audiencia donde escuchó a las partes interesadas, para luego determinar que las sentencias nacionales reclamadas ante la Corte IDH habían "perdido los efectos que les son propios" ${ }^{\prime 31}$. Esto es interesante, pues la Corte Suprema no afirmó que ella misma dejaba sin efecto sus sentencias en atención a lo dispuesto por la Corte IDH, sino que dio a entender que las sentencias habían perdido ya sus efectos, y que ella sólo reconocía esta pérdida. De este modo, la Corte Suprema consideró que las decisiones de la Corte IDH tienen un efecto directo a nivel nacional, por lo que termina considerando a la Corte IDH como un superior jerárquico en materia de derechos humanos.

Esta decisión nos parece errada, puesto que uno de los principios fundamentales del Derecho Público dispone que los órganos del Estado pueden hacer sólo aquello que les está permitido (en contraposición al principio fundamental del Derecho privado, que dispone que las personas pueden hacer todo aquello que no esté prohibido). Teniendo esto en consideración, debe notarse que ninguna norma constitucional ni legal de Chile establece expresamente que la Corte Suprema tenga poder para declarar que una sentencia ha "perdido sus efectos" (aunque el artículo 5.2 de la Constitución de Chile puede confundir a algunos ${ }^{32}$ ). Más aún, el ordenamiento chileno sólo permite que un tribunal internacional tenga la última palabra - pasando por sobre lo que disponga la Corte Suprema - en el caso de la Corte Penal Internacional, y para que ello fuera así, fue necesario reformar previamente la Constitución chilena ${ }^{33}$.

La Corte Suprema de Chile, por su parte, alegó que ella debía encontrar la forma de dar cumplimiento a lo dispuesto por la Corte IDH, en atención a la falta de actuación del Legislativo (el Poder del Estado llamado a determinar cómo hacer efectivas las sentencias de la Corte IDH). La Corte Suprema afirmó que el Legislativo debiera haber establecido un mecanismo para dar cumplimiento a las sentencias de la Corte IDH, y que

30 CORTE INTERAMERICANA DE DERECHOS HUMANOS. Caso Norín Catrimán y Otros (Dirigentes, Miembros y Activista del Pueblo Indígena Mapuche) vs. Chile, Fondo, Reparaciones y Costas, Serie $C \mathrm{n}^{\circ} 279$, párr. 422. Publicado en 29 may. 2014.

31 CHILE. Corte Suprema de Chile, Antecedente Administrativo, AD-1386-2014, visto nº 5.

32 Algunos pueden pensar que dicho artículo implica que las sentencias de la Corte IDH se constituye automáticamente en Derecho superior a la Constitución, pero tal interpretación es errada. El artículo 5.2 dispone: "El ejercicio de la soberanía reconoce como limitación el respeto a los derechos esenciales que emanan de la naturaleza humana. Es deber de los órganos del Estado respetar y promover tales derechos, garantizados por esta Constitución, así como por los tratados internacionales ratificados por Chile y que se encuentren vigentes". Como se puede observar, esta norma no dispone que las sentencias de la Corte IDH tengan un valor inmediato a nivel nacional. Solo afirma que los derechos esenciales que emanan de la naturaleza humana (incluidos los que se encuentren reconocidos en tratados ratificados por Chile) limitan el ejercicio de la soberanía. Así, por una parte, debe notarse que las sentencias de la Corte IDH no son tratados internacionales, y que ellas no siempre se refieren a derechos que emanen de la naturaleza humana. Además, las reparaciones que ordena la Corte no son derechos humanos, sino que mecanismos para tratar de revertir los efectos de las violaciones.

33 Véase la disposición transitoria vigésimocuarta de la Constitución Política de la República de Chile, así como el caso que determinó la necesidad de aprobar esa disposición transitoria (CHILE. Tribunal Constitucional de Chile, Requerimiento, Rol n 346). 
su omisión debía ser reparada por la Corte Suprema. Esta decisión viola el principio del Derecho Público y la separación de poderes, pues ambos impiden que unos poderes del Estados "suplan" lo que deben hacer otros, puesto que el omitir ejercer una función es ya hacer uso de la misma. En efecto, al no actuar, el Legislativo podría haber estado tratando de enviar la señal de que la Corte IDH estaba actuando ultra vires al ordenar dejar sin efecto sentencias de nuestro máximo tribunal. La "falta de actuación" también podría haber sido una maniobra del Legislativo - en el sistema de pesos y contrapesos que genera la separación de poderes de las democracias modernas - para tratar de contrarrestar un ejercicio inadecuado de potestades por parte de otro Poder del Estado.

A nuestro juicio, para cumplir con lo ordenado por la Corte IDH, era necesario que el Congreso le diera tal atribución a la Corte Suprema, por ejemplo, modificando las causales del recurso de revisión. Ello habría permitido cumplir con la sentencia de la Corte IDH, sin afectar nuestro Estado de Derecho. Por su parte, lo más que podría haber hecho la Corte Suprema habría sido hacer presente al resto de los Poderes del Estado que ella estaba atada de manos, de modo que se tratara de presionar al Poder Legislativo en la materia.

Más allá de si se considera o no que el Estado debe contar con un sistema legal para dar cumplimiento a las órdenes de la Corte IDH, nos parece fundamental que se respete el Estado de Derecho a nivel interno, pues ese es un derecho humano sin el cual los demás valen poco. Frente a esto algunos podrán alegar que el artículo 27 de la Convención de Viena sobre el Derecho de los Tratados ${ }^{34}$ exige otorgar jerarquía supralegal a lo que diga la Corte IDH, o considerar que sus resoluciones son autoejecutables. Sin embargo, eso es un error. En efecto, la regla del artículo 27 "solo establece una norma obvia de responsabilidad internacional que se basa en el hecho de que el derecho doméstico de los Estados no tiene fuerza normativa en el derecho internacional" ${ }^{25}$. Dicha norma, en ningún caso, buscó darle aplicación directa en el ámbito interno al Derecho internacional o a las resoluciones de órganos internacionales.

\subsection{Control de convencionalidad y ordenamiento jurídico chileno}

Por último, al hablar sobre el modo como Chile cumple con las sentencias de la Corte IDH, es importante hacer una referencia al tema del control de convencionalidad. La doctrina jurídica chilena está dividida en cuanto a su aplicabilidad, al menos en los términos que establece la Corte IDH, es decir, afirmando que los órganos nacionales

\footnotetext{
34 Que dispone que "[u]na parte no podrá invocar las disposiciones de su derecho interno como justificación del incumplimiento de un tratado".

35 FUENTES TORRIJO, Ximena. Una Nueva Constitución para Chile y el Diseño de un Esquema de Incorporación del Derecho Internacional al Sistema Jurídico Chileno. En: CHÍA, Eduardo A.; QUEZADA, Flavio (eds.). Propuestas para una Nueva Constitución (Originada en Democracia), Instituto Igualdad - Facultad de Derecho Universidad de Chile - Friedrich Ebert-Stiftung, Santiago, p. 174-175, 2015.
} 
tienen la obligación de cumplir con lo que disponga dicha corte, incluso pasando por encima de lo que ordene la legislación nacional. Una parte importante de la doctrina chilena se pronuncia en contra del control de convencionalidad en tales términos ${ }^{36}$. Este rechazo puede deberse al hecho de que en Chile no existe un control de constitucionalidad difuso, sino que solo uno concentrado ${ }^{37}$, lo que hace más ajena la idea de un control de convencionalidad difuso, como lo plantea la Corte IDH.

Por su parte, los tribunales superiores chilenos no han recogido esta doctrina de la Corte IDH, al menos, en la extensión que le da dicha corte. Así, por ejemplo, en la decisión de la Corte Suprema a la que recién aludimos (la relacionada con el caso Norín (atrimán), se dice expresamente que:

mediante el control de convencionalidad, los jueces nacionales forman parte del sistema interamericano en la protección de los estándares de cumplimiento y garantía de tales derechos, dependiendo las consecuencias de este análisis de las funciones que cada operador de justicia tiene, siendo obligación de todos, las autoridades e integrantes del Estado, interpretar sistemática e integralmente las disposiciones que informan el sistema jurídico, de forma tal que sus determinaciones guarden la mayor correspondencia y compatibilidad con las obligaciones internacionales adquiridas soberanamente por éste ${ }^{38}$.

Aquí se puede observar que la Corte Suprema adopta una concepción acotada del control de convencionalidad, es decir, una que establece que los tribunales deben ejercer el control dentro del marco de sus competencias específicas, y que los órganos no judiciales deben tratar de interpretar sus obligaciones en forma coherente con las decisiones de la Corte IDH. Esto excluye una interpretación más extensiva del control de convencionalidad, según la cual todos los órganos del Estado podrían dejar sin efecto normas nacionales, en pos de darle aplicación a los estándares establecidos por la Corte IDH.

\footnotetext{
36 Por ejemplo, SILVA ABBOT, Max. Control de Convencionalidad Interno y Jueces Locales: Un Planteamiento Defectuoso. Estudios Constitucionales, vol. 14, n. 2, p. 101-141, jul. 2016; FUENTES TORRIJO, Ximena. International and Domestic Law: Definitely an Odd Couple. Revista Jurídica de la Universidad de Puerto Rico, vol. 77, p. 483-505, 2008; CONTESSE, Jorge. The International Authority of the Inter-American Court of Human Rights: A Critique of the Conventionality Control Doctrine. The International Journal of Human Rights, vol. 22, n. 9, dic. 2018.

37 Art. 93, Constitución Política de la República de Chile.

38 CHILE. Corte Suprema de Chile, Antecedente Administrativo, AD-1386-2014, visto n 9.
} 


\section{DECLARACIÓN LIDERADA POR CHILE SOBRE MEJORAS AL SIS- TEMA INTERAMERICANO}

\subsection{Cuestiones generales}

Atendido que Chile exhibe un alto grado de cumplimiento de las reparaciones ordenadas por la Corte IDH, algunos consideran paradojal que este Estado esté liderando la declaración en la que, junto con Argentina, Brasil, Colombia y Paraguay, se plantean sugerencias al sistema interamericano de derechos humanos. Sin embargo, la paradoja no es tal, si consideramos que un Estado que no le presta mayor atención a lo que ordena la Corte IDH no tendrá gran incentivo en velar por que el Sistema interamericano funcione bien. En cambio, serán los Estados que se toman en serio a la Corte $\mathrm{IDH}$ - los que respetan sus decisiones - los que deben estar más interesados en que el Sistema opere adecuadamente. Por eso, no debe ser casualidad que la misma declaración afirme explícitamente:

su profundo y permanente compromiso con el valor normativo de [la Convención Americana de Derechos Humanos], en cuanto representa el objeto del consentimiento de los Estados que dieron origen al sistema interamericano de protección de los Derechos Humanos, y con el cumplimiento de su obligación de asegurar a todos, dentro de sus respectivas jurisdicciones, los derechos y libertades definidos en la Convención. ${ }^{39}$

Además, si se revisa el fondo de la Declaración queda claro que todas las inquietudes que plantea son atendibles, y es por eso que todas - o al menos la mayoría de éstas - han sido expuestas por, al menos, uno de los jueces de la Corte IDH en sus votos separados. No obstante esto, bastantes personas han afirmado que estos planteamientos buscan horadar el Sistema interamericano. Tales aprensiones son infundadas, pues es razonable que Estados plenamente democráticos hagan notar deficiencias a órganos que actúan fuera de un sistema de pesos y contrapesos, y que, por lo mismo, no están diseñados para que haya una voz de alerta intra-sistema en caso de que algún órgano se exceda en sus funciones. Es más, los Estados europeos tienen la práctica de hacer declaraciones y reformas que apuntan a mejorar su sistema regional de derechos humanos. Ello se observa, por ejemplo, en las declaraciones de Brighton

39 GOBIERNO NACIONAL DE PARAGUAY. Gobiernos de Argentina, Brasil, Chile, Colombia y Paraguay se Manifiestan sobre el Sistema Interamericano de Derechos Humanos. Gobierno Nacional de Paraguay, Asunción, Abr. 24, 2019. Disponible en <https://www.mre.gov.py/index.php/noticias-de-embajadas-y-consulados/gobiernos-de-argentina-brasil-chile-colombia-y-paraguay-se-manifiestan-sobre-el-sistema-interamericano-de-derechos-humanos>. Acceso en: 6 ago. 2019. 
y Copenhague ${ }^{40}$, y en los múltiples protocolos referidos a la Convención Europea de Derechos Humanos.

Para demostrar que no constituye una paradoja que un Estado comprometido con el sistema interamericano promueva la declaración de los cinco Estados, analizaremos si la Declaración es razonable, pues si lo fuera, la intención de los Estados que la proponen puede ser genuinamente mejorar el sistema. Para mostrar la razonabilidad de la Declaración, revisaremos cada uno de los cinco puntos que plantea.

\subsection{Consideración de cada una de las cinco propuestas}

Cada uno de los temas planteados por la Declaración requieren de un tratamiento en profundidad, que no puede hacerse en un trabajo que busca tratarlos en conjunto. Por eso, sólo podremos referirnos a ellos de forma somera, de modo de analizar sintéticamente si los puntos observados en esta Declaración son razonables. Hacemos presente que no buscamos convencer a los lectores sobre la conveniencia o inconveniencia de cada punto en particular, sino sólo de que son inquietudes atendibles, y que, por lo mismo, pueden ser planteadas por Estados comprometidos con el éxito del sistema interamericano de derechos humanos.

\subsubsection{Principio de subsidiariedad}

El primer punto que plantea la Declaración, es que los Estados firmantes:

Subrayan que el principio de subsidiariedad, que da sustento a los presupuestos jurídicos de admisibilidad de una petición, tiene una doble dimensión. Por un lado, supone que el Estado concernido tiene la obligación de investigar toda violación a la Convención que acontezca en su territorio, y, por el otro, que dicho Estado tiene el derecho de que su propio sistema jurisdiccional resuelva la situación antes de verse sometido a una instancia internacional.

Como se puede apreciar, los Estados hacen referencia al principio de subsidiariedad, que para efectos del Derecho internacional de los derechos humanos podría ser caracterizado como el principio que consagra el poder de las instituciones internacionales para "asistir a los Estados en el cumplimiento de sus obligaciones en materia de derechos humanos" 41 , pero que reconoce que éstos tienen "amplios espacios de liber-

40 HIGH LEVEL CONFERENCE ON THE FUTURE OF THE EUROPEAN COURT OF HUMAN RIGHTS. Brighton Declaration, Abr. 2012. Disponible en <https://www.echr.coe.int/Documents/2012_Brighton_FinalDeclaration_ENG.pdf>. Acceso en: 26 jul. 2019. y HIGH LEVEL CONFERENCE MEETING IN COPENHAGEN. Copenhagen Declaration, Abr. 2018. Disponible en <https://www.echr.coe.int/Documents/Copenhagen_Declaration_ENG. pdf>. Acceso en: 26 jul. 2019.

41 GONZÁLEZ DOMíNGUEZ, Pablo. Reconfiguración de la relación entre el derecho internacional de los derechos humanos y el derecho nacional sobre la base del principio de subsidiariedad. Anuario Mexicano de 
tad [...] para definir el alcance y los mecanismos institucionales de cumplimiento de dichas obligaciones". 42

“El principio de subsidiariedad tiene una faceta positiva y otra negativa, es decir, impone un deber de actuar y un deber de abstenerse de actuar"43. La declaración de los cinco Estados da a entender que está más preocupada por lo que ocurre en la faceta negativa del principio de subsidiariedad, es decir, que le interesa la idea de que el Sistema interamericano no debe intervenir en casos en que el Estado aún está haciendo uso de los mecanismos internos para resolver las eventuales violaciones a los derechos humanos. Se solicita, en consonancia con lo que dispone la Convención Americana sobre Derechos Humanos, que el Sistema exija verdaderamente que quienes presenten una petición hayan agotado previamente todos los recursos judiciales internos antes de hacerlo. Es cierto que la Convención Americana reconoce ciertas excepciones a la exigencia de haber agotado los recursos internos ${ }^{44}$, pero hay casos en que la CIDH y la Corte hacen excepciones que van más allá de lo que dice la Convención, por ejemplo, aceptando que los recursos se hayan agotado durante la tramitación de la petición ante la $\mathrm{CIDH}$, con tal de que ello ocurra antes del estudio formal de admisibilidad ${ }^{45}$. Otro modo en el que se ha hecho caso omiso a la obligación de agotar previamente los recursos, es al dar por renunciada la excepción de agotamiento de recursos sin que ello haya sido la intención del Estado ${ }^{46}$, o dando por cumplida esta obligación al acudir exclusivamente a recursos de naturaleza cautelar (como la tutela), existiendo instancias de lato conocimiento a las que también se podía recurrir ${ }^{47}$. La falta de agotamiento de recursos internos por parte del Sistema ha sido criticado, incluso, por jueces de la Corte, por ejemplo, en el voto del juez Vio Grossi en el caso Díaz Peña vs. Venezuela ${ }^{48}$.

\footnotetext{
Derecho International, vol. XVII, p. 730, dic. 2017.

42 GONZÁLEZ DOMÍNGUEZ, Pablo. Reconfiguración de la relación entre el derecho internacional de los derechos humanos y el derecho nacional sobre la base del principio de subsidiariedad. Anuario Mexicano de Derecho International, vol. XVII, p. 730, dic. 2017.

43 PAÚL DÍAZ, Álvaro. La Corte Interamericana in Vitro: Comentarios sobre su Proceso de Toma de Decisiones a Propósito del Caso Artavia. Derecho Público Iberoamericano, vol. 2, p. 333, abr. 2013.

44 Art. 46.2 de la Convención Americana sobre Derechos Humanos.

45 PAÚL, Álvaro. The Inter-American Commission on Human Rights' Initial Review of Petitions, Its Backlog, and the Principle of Subsidiarity. The George Washington International Law Review, vol. 49, p. 48-51, feb. 2016.

46 Véase CORTE INTERAMERICANA DE DERECHOS HUMANOS. Caso Masacre de Mapiripán vs. Colombia, Excepciones Preliminares, Serie C n 122, párrs. 20, 23 y 30. Publicado en 7 mar. 2005.

47 CORTE INTERAMERICANA DE DERECHOS HUMANOS. Caso Duque vs. Colombia, Excepciones Preliminares, Fondo, Reparaciones y Costas, Serie C n 310, párrs. 28-33. Publicado en 26 feb. 2016.

48 Voto individual disidente del juez Vio Grossi en CORTE INTERAMERICANA DE DERECHOS HUMANOS. Caso Díaz Peña vs. Venezuela, Excepciones Preliminares, Fondo, Reparaciones y Costas, Serie $C n^{\circ} 244$. Publicado en 26 jun. 2012.
} 


\subsubsection{Legítima autonomía}

En segundo lugar, los cinco Estados:

[c]onsideran que se debe respetar el legítimo espacio de autonomía del que disponen los Estados para asegurar a todas las personas sometidas a su jurisdicción, a través de sus propios procesos democráticos, los derechos y garantías consagrados en la Convención de conformidad a sus ordenamientos constitucionales.

Al solicitar que se respete el "legítimo espacio de autonomía del que disponen los Estados" para asegurar los derechos según sus procesos democráticos, los cinco Estados no están pidiendo que el sistema interamericano les dé carta blanca para violar algunos derechos. Están solicitando que la Corte IDH no imponga visiones únicas de los derechos humanos, cuando ellos tienen diversos modos legítimos de ser interpretados. En efecto, si bien hay derechos que no admiten más de una interpretación - como podría ser el caso de la obligación de conceder una indemnización por error judicial a quien se haya condenado injustamente por sentencia penal firme - , gran parte de los derechos permite más de una lectura. La Corte olvida esta realidad, y termina afirmando que la Convención Americana exige cosas tan detalladas, como si se debe o no adoptar la doctrina del fruto del árbol envenenado para desincentivar malas prácticas investigativas (cuestión bastante discutible) ${ }^{49}$. Por eso, los Estados solicitan que cuando la Convención Americana permita diversas interpretaciones legítimas, ellos puedan, democráticamente, determinar cuál adoptar.

Quizá un modo de entender esto, es analizando un ejemplo de lo que ocurre en el sistema europeo de derechos humanos. El artículo 9 del Convenio Europeo de Derechos Humanos dispone que las personas tienen derecho a la "libertad de pensamiento, de conciencia y de religión" ${ }^{\prime 50}$. El Convenio describe este derecho en dos párrafos, pero a pesar de dicha extensión, puede interpretarse de maneras muy variadas. Eso permite que haya Estados europeos que, no obstante ser bastante respetuosos de la libertad de religión, tengan aproximaciones muy diversas a cómo llevar adelante su relación con el hecho religioso. Por una parte, hay países como Francia, que optan por que el Estado evite cualquier expresión religiosa, mientras que otros, igual o más respetuosos de la libertad religiosa, como Dinamarca y Gran Bretaña, cuentan con una religión

\footnotetext{
49 Véase CORTE INTERAMERICANA DE DERECHOS HUMANOS. Caso Cabrera García y Montiel Flores vs. México, Excepciones Preliminares, Fondo, Reparaciones y Costas, Serie $C n^{\circ} 220$, párr. 167. Publicado en 26 nov. 2010. En esta materia, véase PAÚL, Álvaro. Admissibility of Evidence before the Inter-American Court of Human Rights, Revista Direito GV, vol. 13, n. 2, p. 663-673, mai-ago 2017.

50 Art. 9.1 del Convenio para la Protección de los Derechos Humanos y de las Libertades Fundamentales. Modificado por los Protocolos nos 11 y 14.
} 
oficial y permiten que el Estado cuente con tradiciones públicas y símbolos de naturaleza religiosa ${ }^{51}$.

La riqueza y diversidad de tradiciones como la recién descrita es permitida sólo gracias a una doctrina propia del sistema europeo llamada margen de apreciación ${ }^{52}$, que la Corte IDH no ha recogido. El margen de apreciación puede definirse como la deferencia que tiene el Tribunal Europeo de Derechos Humanos con los Estados bajo su jurisdicción, para permitirles definir en cierta extensión el contenido de los derechos consagrados en el Convenio Europeo de Derechos Humanos, o para permitirles determinar el modo como ponderarlos cuando entran en juego con otros derechos.

En definitiva, en este punto, la Declaración de los cinco Estados pide que el sistema interamericano de derechos humanos emule a su par europeo y su doctrina del margen de apreciación. A algunos puede gustarles esta idea y a otros no ${ }^{53}$, pero es una aspiración legítima, y que de ningún modo refleja mala fe por parte de los Estados.

\subsubsection{Atraso procesal y garantías}

Uno de los problemas más notorios del sistema interamericano es el del llamado "atraso procesal" de la CIDH. En ese contexto, la Declaración señala:

Igualmente, consideran que, en el contexto de las medidas adoptadas para reducir el atraso procesal en el ámbito de la Comisión, se debe garantizar el derecho a la defensa, la seguridad jurídica y la igualdad procesal.

La demora en la tramitación de las peticiones individuales es un problema patente del Sistema. En efecto, hasta hace poco, la CIDH demoraba unos cinco años en revisar las simples formalidades de un caso (antes de siquiera analizar su admisibilidad en detalle $)^{54}$. Por eso, la CIDH está esforzándose en reducir su demora a través de varios

\footnotetext{
51 Dos casos relevantes en la materia sirven para notar el margen que concede el Tribunal Europeo: TRIBUNAL EUROPEO DE DERECHOS HUMANOS. Caso Leyla Şahin vs. Turquía, Acción n 44774/98. Publicado en 10 nov. 2005. y TRIBUNAL EUROPEO DE DERECHOS HUMANOS. Caso Lautsi y otros vs. Italia, Acción n $30814 / 06$. Publicado en 18 mar. 2011.

52 Para un análisis de esta doctrina, puede verse BREMS, Eva. The Margin of Appreciation Doctrine in the Case-Law of the European Court of Human Rights. Heidelberg Journal of International Law, vol. 56, p. 240-314, 1996.

53 Para un ejemplo de los primeros, véase NúÑEZ POBLETE, Manuel. Sobre la Doctrina del Margen de Apreciación Nacional. La Experiencia Latinoamericana Confrontada y el Thelos Constitucional de una Técnica de Adjudicación del Derecho Internacional de los Derechos Humanos. En: NÚÑEZ POBLETE, Manuel; ACOSTA ALVARADO, Paola Andrea (eds.). El Margen de Apreciación en el Sistema Interamericano de Derechos Humanos: Proyecciones Regionales y Nacionales, Universidad Nacional Autónoma de México. Instituto de Investigaciones Jurídicas, México, p. 3-49, 2012. Para un ejemplo de los segundos, véase NASH ROJAS, Claudio. La Doctrina del Margen de Apreciación y su Nula Recepción en la Jurisprudencia de la Corte Interamericana de Derechos Humanos. ACDI-Anuario Colombiano de Derecho Internacional, vol. 11, p. 71-100, 2018.

54 PAÚL, Álvaro. The Inter-American Commission on Human Rights'Initial Review of Petitions, Its Backlog, and the Principle of Subsidiarity. The George Washington International Law Review, vol. 49, p. 29, feb. 2016.
} 
mecanismos, como inyectando recursos para que más personal se dedique a analizar las peticiones atrasadas ${ }^{55}$. Los Estados parecen estar preocupados de que algunas de las reformas en las que está embarcada la $\mathrm{CIDH}$ puedan afectar el derecho a la defensa, la seguridad jurídica y la igualdad procesal. En este punto no es fácil saber, precisamente, a qué se refieren los cinco Estados, pues no están planteando una crítica que se haya hecho en forma clara y reiterada al Sistema interamericano, ya sea por la doctrina o por quienes acuden ante él.

Los esfuerzos de la CIDH para reducir su atraso han estado centrados en analizar peticiones que están en la etapa de revisión inicial. Esto ha hecho que un gran número de asuntos pasen a la etapa de admisibilidad. Por ello, es posible aventurarse a decir que los cinco Estados estarían interesados en que se respete adecuadamente el debido proceso en alguna de esas dos etapas.

La mayoría de las personas que hayan presentado peticiones ante el Sistema interamericano podrían confirmar que la etapa de revisión inicial, es decir, el estudio preliminar de admisibilidad que se tramita antes de que el asunto se notifique al Estado y pase al estudio pormenorizado de admisibilidad ${ }^{56}$, es una etapa que carece de transparencia y claridad. Al final de dicha revisión inicial, las peticiones rechazadas no reciben un informe detallado de los motivos por los cuales se desechan; sólo se indica a grandes rasgos el motivo por el que se las rechaza, a pesar de que la Secretaría cuenta con un informe más detallado, que no es notificado a los peticionarios. Esta falta de transparencia afecta el debido proceso y la certeza jurídica, aunque es un tema que más interesaría a los peticionarios que a los Estados.

Desconocemos cuáles pueden ser los problemas que afecten a los Estados durante el procedimiento de admisibilidad propiamente tal. Sin embargo, en todo lo que diga relación con sus procedimientos, la CIDH debiera ser muy cuidadosa, pues el debido proceso es uno de los pocos derechos humanos que puede violar un órgano como la $\mathrm{CIDH}$ (y éste es claramente violado con la demora en la tramitación de las peticiones individuales). Por eso, la CIDH debiera ser muy diligente para no violar el debido proceso producto de vulneraciones al derecho a la defensa, la seguridad jurídica o la igualdad procesal.

55 COMISIÓN INTERAMERICANA DE DERECHOS HUMANOS. CIDH concluye 2 años de su Programa de Superación del Atraso Procesal y anuncia nuevas acciones aprobadas tras una segunda etapa de consultas participativas, Washington, Dic. 2, 2018. Disponible en <http://www.oas.org/es/cidh/prensa/comunicados/2018/257.asp >. Acceso en: 10 ago. 2019.

56 PAÚL, Álvaro. The Inter-American Commission on Human Rights'Initial Review of Petitions, Its Backlog, and the Principle of Subsidiarity. The George Washington International Law Review, vol. 49, p. 23, feb. 2016. 


\subsubsection{Derechos y su aplicación}

El cuarto punto de la Declaración es el más complejo, pues se refiere a varios temas distintos. En efecto, los cinco Estados:

[d]estacan la importancia de una estricta aplicación de las fuentes del Derecho Internacional de los Derechos Humanos y del reconocimiento del margen de apreciación de los Estados en el cumplimiento de las obligaciones que establece la Convención. Asimismo, recuerdan que las resoluciones y sentencias de los órganos del sistema interamericano sólo tienen efectos para las partes del litigio.

Como se observa, aquí los Estados buscan: a) que el Sistema aplique estrictamente las fuentes del Derecho internacional de los derechos humanos; b) que se reconozca el margen de apreciación, y c) hacer una referencia velada al control de convencionalidad. Ahora nos referiremos individualmente a estos tres planteamientos.

En relación con el primero, se le exige al Sistema que aplique estrictamente las fuentes del Derecho internacional. Este punto podría referirse a dos cosas. En primer lugar, puede buscar resaltar que la Corte IDH sólo puede aplicar las fuentes respecto de las cuales tiene jurisdicción, pues no puede aplicar instrumentos - aunque sean fuente formal del Derecho - que no estén destinados a ser aplicados por ella ${ }^{57}$. En segundo lugar, puede referirse al uso que le da la Corte IDH a cualquier tipo de instrumento que tenga visos de internacionalidad o de legalidad, para interpretar evolutivamente la Convención Americana de Derechos Humanos, y así afirmar que ella consagra algún derecho que no se encuentra explicitado en la Convención. En efecto, la Corte suele hacer esto, incluso, en materias altamente discutibles, propias del debate político ${ }^{58}$. Así, al proclamar derechos que no están establecidos en las fuentes del Derecho internacional que ella debe aplicar, la Corte IDH ha ampliado enormemente el catálogo de supuestos derechos por los que ella debiera velar ${ }^{59}$. Una de las recientes ampliaciones de la Corte es considerar justiciables los derechos económicos, sociales y culturales, basándose en el artículo 26 de la Convención Americana, cuestión en la que han manifestado sus reparos los jueces Vio Grossi y Sierra Porto, de la misma Corte IDH ${ }^{60}$.

\footnotetext{
57 PAÚL DÍAZ, Álvaro. La Corte Interamericana in Vitro: Comentarios sobre su Proceso de Toma de Decisiones a Propósito del Caso Artavia. Derecho Público Iberoamericano, vol. 2, p. 310-314, abr. 2013.

58 PAÚl DÍAZ, Álvaro. La Corte Interamericana in Vitro: Comentarios sobre su Proceso de Toma de Decisiones a Propósito del Caso Artavia. Derecho Público Iberoamericano, vol. 2, p. 317-320, abr. 2013.

59 Esto se puede observar en forma muy gráfica en PAÚL, Álvaro. The American Convention on Human Rights: Updated by the Inter-American Court. Juris Dictio, vol. 20, p. 53-86, dec. 2017.

60 Véanse los votos disidentes de estos jueces en el caso CORTE INTERAMERICANA DE DERECHOS HUMANOS. Caso Lagos del Campo vs. Perú, Excepciones Preliminares, Fondo, Reparaciones y Costas, Serie $\mathrm{C} \mathrm{n}{ }^{\circ} 340$. Publicado en 31 ago. 2017.
} 
Para ampliar su jurisdicción, muchas veces la Corte IDH se basa en una interpretación errada del artículo 29 de la Convención Americana de Derechos Humanos, alegando que estos nuevos derechos estarían implícitamente reconocidos en la Convención ${ }^{61}$. En general, la Corte considera que el artículo 29 es una especie de norma de reenvío, una disposición que sería prácticamente única en el Derecho internacional. Lo interesante es que el artículo 29 no es ni una norma de reenvío ni una que no se encuentre en otros tratados. Desafortunadamente, no podemos tratar este tema en este trabajo, pues requiere de un estudio en sí mismo, pero ya se ha escrito algo sobre el punto ${ }^{62}$.

En relación con el segundo reparo, esto es, la ausencia del margen de apreciación, ya nos hemos referido al tema al hablar sobre el legítimo espacio de autonomía que tienen los Estados al momento de interpretar la Convención Americana. Por eso, pasaremos inmediatamente a tratar el tercer planteamiento, referido al control de convencionalidad, tema al que ya nos referimos brevemente. Recapitulando, el control de convencionalidad es una doctrina elaborada por la Corte IDH que plantea que sus sentencias crean una jurisprudencia que vincula a todos los Estados parte de la Convención Americana de Derechos Humanos, y que debe ser aplicada por todos los órganos internos de los Estados, incluso aunque ello les exija actuar en contra de su legislación nacional, con independencia de si el ordenamiento jurídico interno les concede o no ese poder a los órganos estatales ${ }^{63}$.

La doctrina del control de convencionalidad carece de sustento en la Convención Americana de Derechos Humanos; muy por el contrario, la Convención establece en su artículo 68.1 que los Estados están sólo obligados "a cumplir la decisión de la Corte en todo caso en que sean partes". Por eso, aunque la doctrina del control de

61 Sobre los derechos implícitos y la Corte IDH, véase CANDIA FALCÓN, Gonzalo. Derechos Implícitos y Corte Interamericana de Derechos Humanos: Una Reflexión a la Luz de la Noción de Estado de Derecho. Revista Chilena de Derecho, vol. 42, n. 3, p. 873-902, dic. 2015.

62 Sobre el artículo 29 véase PAÚL, Álvaro. Elementos para Reinterpretar el Artículo 29 de la Convención Americana de Derechos Humanos. En: ACOSTA ALVARADO, Paola Andrea; DELPIANO LIRA, Cristián (eds.). América Latina y el Orden Mundial Contemporáneo, Universidad Externado de Colombia - Sociedad Latinoamericana de Derecho Internacional, Bogotá, p. 131-147, 2017.

63 Para una explicación detallada de esta doctrina, véase DULITZKY, Ariel E. ¿An Inter-American Constitutional Court? The Invention of the Conventionality Control by the Inter-American Court of Human Rights. Texas International Law Journal, vol. 50, n. 1, p. 45-94, 2015. 
convencionalidad tiene muchos adeptos ${ }^{64}$, tiene también muchos $\operatorname{críticos}^{65}$. Los cinco Estados, al referirse a este tema en su declaración no hacen más que ponerse del lado de quienes critican la doctrina, y le piden a la Corte IDH que adopte un enfoque restrictivo al momento de aplicarla ${ }^{66}$. Nuevamente, los lectores podrán estar o no de acuerdo con esta posición, pero ella es compartida por bastantes autores, por lo que no puede considerarse que los cinco Estados busquen minar el sistema interamericano al proponer este punto.

\subsubsection{Reparaciones}

Finalmente, los cinco Estados:

[e]nfatizan la importancia del debido conocimiento y consideración de las realidades políticas, económicas y sociales de los Estados por parte de los órganos del sistema interamericano de derechos humanos. En este marco, resaltan la necesidad de que las formas de reparación guarden una debida proporcionalidad y respeten tanto los ordenamientos constitucionales y jurídicos de los Estados, como las exigencias propias del Estado de Derecho.

Con este último punto, los Estados le piden a la Corte IDH que, en materia de reparaciones, tenga en cuenta las realidades nacionales de los Estados. Ellos solicitan esto porque la Corte, en variadas ocasiones, ha ordenado reparaciones sin ponderar los efectos que ellas tienen, o si los Estados se encuentran en condiciones de cumplirlas, o si no sería más fácil que ellos mismos determinaran cómo llegar al resultado buscado por la Corte. Por ejemplo, a ciertos Estados se les ha obligado a que implementen planes nacionales en materia de políticas públicas, sin tener en consideración los recursos ni las necesidades de tales Estados. Puede decirse que esto le ocurrió a Costa Rica, pues la Corte le pidió que implementara en su sistema de salud público un mecanismo

64 Por ejemplo: NOGUEIRA ALCALÁ, Humberto. Los Desafíos del Control de Convencionalidad del Corpus luris Interamericano para las Jurisdicciones Nacionales. Boletín Mexicano de Derecho Comparado, vol. Año XLV, n. 135, p. 1167-1220, sep.-dic. 2012; SAGÜÉS, Néstor Pedro. Obligaciones Internacionales y Control del Convencionalidad. Estudios Constitucionales, vol. 8, n. 1, p. 117-136, 2010; FERRER MAC-GREGOR POISOT, Eduardo. El Control de Convencionalidad en la Jurisprudencia de la Corte Interamericana de Derechos Humanos (A Una Década de su Creación: 2006-2016). En: HENRÍQUEZ VIÑAS, Miriam; MORALES ANTONIAZZI, Mariela. El Control de Convencionalidad: Un Balance Comparado a 10 Años de Almonacid Arellano vs. Chile, Ediciones Der, Santiago, p. 37-69, 2017.

65 Por ejemplo: DULITZKY, Ariel E. ¿An Inter-American Constitutional Court? The Invention of the Conventionality Control by the Inter-American Court of Human Rights. Texas International Law Journal, vol. 50, n. 1, p. 45-94, 2015; CASTILLA JUÁREZ, Karlos A. ¿Control Interno o Difuso de Convencionalidad? Una Mejor Idea: La Garantía de Tratados. Anuario Mexicano de Derecho International, vol. XIII, p. 51-97, dic. 2013; SILVA ABBOT, Max. Control de Convencionalidad Interno y Jueces Locales: Un Planteamiento Defectuoso. Estudios Constitucionales, vol. 14, n. 2, p. 101-141, jul. 2016.

66 Sobre el enfoque amplio y los restrictivos, véase PAÚL, Álvaro. The Emergence of a More Conventional Reading of the Conventionality Control Doctrine. Revue Générale de Droit, vol. 49, p. 275-302, feb. 2019. 
concreto, que tiene alternativas más baratas y efectivas, sin tener en consideración que sólo tres Estados — de los más ricos del Continente - estaban recién planeando implementar este sistema ${ }^{67}$. La Corte ni siquiera se planteó si Costa Rica tenía otras necesidades más urgentes.

La Corte IDH también ha ordenado llevar adelante ciertas medidas específicas, como construir monumentos. Uno de los problemas de ordenar este tipo de cosas, es que la Corte desconoce las sensibilidades locales que dichas medidas pueden estimular. Así, por ejemplo, la construcción de ciertos monumentos ha generado gran oposición popular, como cuando la Corte le ordenó a Perú inscribir los nombres de personas condenadas por terrorismo en un monumento ya existente, dedicado a las víctimas del conflicto interno, pues algunas de las personas cuyos nombres se escribieron eran vistas como victimarias ${ }^{68}$.

Por último, también ocurre que la Corte IDH ordena cosas que pueden ser muy difíciles de cumplir en razón del ordenamiento constitucional de un Estado, y que el mismo fin podría obtenerse por otras vías. Por ejemplo, si a la Corte le interesa que en un Estado se deje de aplicar una ley de amnistía, a ella no le debiera interesar mayormente si esto se logra por una derogación explícita de la ley, o si se logra mediante una interpretación vinculante de la máxima autoridad judicial. En cambio, a nivel nacional, esto sí puede ser muy relevante, como ocurriría si es muy difícil obtener las mayorías parlamentarias necesarias. Es cierto que algunos consideran que es bueno que la Corte ordene medidas específicas, para que los Estados estén obligados a procurar una adecuada reparación de las violaciones que cometieron. Sin embargo, es necesario tener cierta confianza en que los Estados, pues al estar más conectados con la realidad nacional, pueden encontrar formas adecuadas de obtener los mismos resultados buscados por la Corte. En ese sentido, es apropiado decir que la deferencia de los tribunales de derechos humanos sobre el modo de llevar a cabo sus sentencias es una forma de abrir el diálogo con los Estados, que redunda en un mejor cumplimiento ${ }^{69}$.

\section{CONCLUSIONES}

Chile es un Estado comprometido con el Sistema Interamericano, cuestión que se observa en el alto porcentaje de sentencias cumplidas que exhibe. Por ello, no sería

\footnotetext{
67 Véase CORTE INTERAMERICANA DE DERECHOS HUMANOS. Caso Artavia Murillo y Otros (Fecundación in vitro) vs. Costa Rica, Excepciones Preliminares, Fondo, Reparaciones y Costas, Serie C n² 257, párrs. 255 y 338. Publicado en 28 nov. 2012.

68 PASQUALUCCI, Jo M. The Practice and Procedure of the Inter-American Court of Human Rights, 2. ed., Cambridge University Press, New York, 2014, pp. 317-318. Véase también CAVALLARO, James L.; BREWER, Stephanie Erin. Reevaluating Regional Human Rights Litigation in the Twenty-First Century: The Case of the Inter-American Court. The American Journal of International Law, vol. 102, n 4, p. 824-825, oct. 2008.

69 FIKFAK, Veronika. Changing State Behaviour: Damages before the European Court of Human Rights. The European Journal of International Law, vol. 29, n. 4, p. 1101, nov. 2018.
} 
razonable inferir a priori que su liderazgo en la redacción de una declaración que formula sugerencias al sistema interamericano de derechos humanos sea mal intencionada. Ello es aún más patente si se nota que las peticiones que se hacen en la declaración son bastante razonables, y han sido planteadas por jueces de la misma Corte IDH, o por parte de cierta doctrina especializada.

Las cuestiones que solicitan los cinco Estados que apoyan esta declaración son: a) que el Sistema sea fiel a su naturaleza subsidiaria, permitiendo que las judicaturas de los Estados resuelvan las violaciones de derechos humanos que ocurran en su territorio, es decir, que se aplique a cabalidad la norma que exige haber agotado los recursos internos antes de poder comparecer ante el Sistema; b) que se reconozca que los Estados tienen una legítima autonomía para interpretar democráticamente los derechos que tienen un contenido abierto; c) que las medidas que adopte la $\mathrm{CIDH}$ para reducir su atraso en la tramitación de peticiones no vulnere las garantías del debido proceso; d) que la CIDH y la Corte IDH apliquen sólo las fuentes del Derecho que deben utilizar; e) que el Sistema adopte la doctrina del margen de apreciación; f) que la Corte adopte una versión acotada del control de convencionalidad, y g) que la Corte IDH sea realista y mesurada al momento de ordenar reparaciones en sus sentencias.

Como se puede observar, los antedichos planteamientos son razonables, por lo que no sustentarían la afirmación de que Chile se encuentre actuando de mala fe. Esto queda particularmente claro al observar que Chile exhibe, en general, un buen cumplimiento de las órdenes de la Corte IDH. Por otro lado, los Estados que cumplen de buena fe las sentencias de un tribunal debieran ser los más atentos en procurar su adecuado funcionamiento, pues los Estados desinteresados en acatar los fallos no se verán mayormente afectados por lo que éstos dispongan. Por eso, puede decirse que los Estados involucrados con el Sistema, que lo toman en serio, buscarán plantear inquietudes sobre su funcionamiento. Eso debiera explicar que Chile lidere la declaración que plantearon cinco Estados de la Región. También explicaría que los Estados comprometidos de Europa suelan presentar este tipo de inquietudes a su sistema regional. Por ello, planteamientos como el de los cinco Estados no deben ser tomados como amenazas, sino que como oportunidades para un diálogo fructífero.

\section{REFERENCIAS}

BREMS, Eva. The Margin of Appreciation Doctrine in the Case-Law of the European Court of Human Rights. Heidelberg Journal of International Law, vol. 56, p. 240-314, 1996.

CANDIA FALCÓN, Gonzalo. Derechos Implícitos y Corte Interamericana de Derechos Humanos: Una Reflexión a la Luz de la Noción de Estado de Derecho. Revista Chilena de Derecho, vol. 42, n. 3, p. 873-902, dic. 2015. 
CASTILLA JUÁREZ, Karlos A. ¿Control Interno o Difuso de Convencionalidad? Una Mejor Idea: La Garantía de Tratados. Anuario Mexicano de Derecho International, vol. XIII, p. 51-97, dic. 2013.

CAVALLARO, James L.; BREWER, Stephanie Erin. Reevaluating Regional Human Rights Litigation in the Twenty-First Century: The Case of the Inter-American Court. The American Journal of International Law, vol. 102, n. 4, p. 768-827, oct. 2008.

CHILE. Corte Suprema de Chile, Antecedente Administrativo, AD-1386-2014.

CHILE. Tribunal Constitucional de Chile, Requerimiento, Rol $\mathbf{n}^{\circ} 346$.

COMISIÓN INTERAMERICANA DE DERECHOS HUMANOS. CIDH concluye 2 años de su Programa de Superación del Atraso Procesal y anuncia nuevas acciones aprobadas tras una segunda etapa de consultas participativas, Washington, Dic. 2, 2018. Disponible en <http://www.oas. org/es/cidh/prensa/comunicados/2018/257.asp>. Acceso en: 10 ago. 2019.

COMISIÓN INTERAMERICANA DE DERECHOS HUMANOS (@CIDH). La CIDH ha recibido una Declaración suscrita por Chile, Argentina, Brasil, Colombia y Paraguay que señala la importancia del $\mathrm{SIDH}$ y hace sugerencias para mejorar su eficacia. La CIDH valora la postura constructiva de los Estados y examinará el tema durante sus próximas Sesiones. Twitter, Abr. 23, 2019. Disponible en: <https://twitter.com/cidh/status/1120750186219868162?lang=en>. Acceso en: 6 ago. 2019.

CORTE INTERAMERICANA DE DERECHOS HUMANOS. Caso Almonacid Arellano y Otros vs. Chile, Excepciones Preliminares, Fondo, Reparaciones y Costas, Serie $C n^{\circ} 154$. Publicado en 26 sep. 2006.

CORTE INTERAMERICANA DE DERECHOS HUMANOS. Caso Artavia Murillo y Otros (Fecundación in vitro) vs. Costa Rica, Excepciones Preliminares, Fondo, Reparaciones y Costas, Serie $\mathrm{C} \mathrm{n}^{\circ}$ 257, párrs. 255 y 338. Publicado en 28 nov. 2012.

CORTE INTERAMERICANA DE DERECHOS humANOS. Caso Atala Riffo e Hijas vs. Chile, Fondo, Reparaciones y Costas, Serie $C n^{\circ}$ 239. Publicado en 24 feb. 2001.

CORTE INTERAMERICANA DE DERECHOS hUMANOS. Caso Atala Riffo e Hijas vs. Chile, Supervisión de Cumplimiento. Publicado en 10 feb. 2017.

CORTE INTERAMERICANA DE DERECHOS HUMANOS. Caso Cabrera García y Montiel Flores vs. México, Excepciones Preliminares, Fondo, Reparaciones y Costas, Serie $C n^{\circ} 220$. Publicado en 26 nov. 2010.

CORTE INTERAMERICANA DE DERECHOS HUMANOS. Caso Claude Reyes y Otros vs. Chile, Fondo, Reparaciones y Costas, Serie C n 151, párrs. 162 y 163. Publicado en 19 sep. 2006.

CORTE INTERAMERICANA DE DERECHOS HUMANOS. Caso Claude Reyes y Otros vs. Chile, Supervisión de Cumplimiento. Publicado en 24 nov. 2008.

CORTE INTERAMERICANA DE DERECHOS hUMANOS. Caso Díaz Peña vs. Venezuela, Excepciones Preliminares, Fondo, Reparaciones y Costas, Serie C n² 244. Publicado en 26 jun. 2012. 
CORTE INTERAMERICANA DE DERECHOS hUMANOS. Caso Duque vs. Colombia, Excepciones Preliminares, Fondo, Reparaciones y Costas, Serie C n 310. Publicado en 26 feb. 2016.

CORTE INTERAMERICANA DE DERECHOS HUMANOS. Caso Lagos del Campo vs. Perú, Excepciones Preliminares, Fondo, Reparaciones y Costas, Serie C n³ 340. Publicado en 31 ago. 2017.

CORTE INTERAMERICANA DE DERECHOS HUMANOS. García Lucero y otras vs. Chile, Supervisión de Cumplimiento. Publicado en 17 abr. 2015.

CORTE INTERAMERICANA DE DERECHOS HUMANOS. Caso Humberto Maldonado Vargas y otros vs. Chile, Fondo, Reparaciones y Costas, Serie C n 300, párr. 167. Publicado en 2 sep. 2015.

CORTE INTERAMERICANA DE DERECHOS HUMANOS. Caso Masacre de Mapiripán vs. Colombia, Excepciones Preliminares, Serie $C \mathrm{n}^{\circ}$ 122. Publicado en 7 mar. 2005.

CORTE INTERAMERICANA DE DERECHOS HUMANOS. Caso Norín Catrimán y Otros (Dirigentes, Miembros y Activista del Pueblo Indígena Mapuche) vs. Chile, Fondo, Reparaciones y Costas, Serie $C n^{\circ} 279$. Publicado en 29 may. 2014.

CORTE INTERAMERICANA DE DERECHOS HUMANOS. Caso Olmedo Bustos y Otros vs. Chile (La Última Tentación de Cristo), Fondo, Reparaciones y Costas, Serie $C n^{\circ} 73$. Publicado en 5 feb. 2001.

CORTE INTERAMERICANA DE DERECHOS HUMANOS. Véanse Olmedo Bustos y Otros vs. Chile (La Última Tentación de Cristo), Supervisión de Cumplimiento. Publicado en 28 nov. 2003.

CORTE INTERAMERICANA DE DERECHOS HUMANOS. Caso Órdenes Guerra y Otros vs. Chile, Fondo, Reparaciones y Costas, Serie C n 372, párr. 124. Publicado en 29 nov. 2018.

CORTE INTERAMERICANA DE DERECHOS hUMANOS. Caso Palamara Iribarne vs. Chile, Fondo, Reparaciones y Costas, Serie $C n^{\circ} 135$. Publicado en 22 nov. 2005.

CORTE INTERAMERICANA DE DERECHOS hUMANOS. Caso Poblete Vilches y Otros vs. Chile, Fondo, Reparaciones y Costas, Serie $\mathrm{Cn}^{\circ}$ 349. Publicado en 8 mar. 2018.

CORTE INTERAMERICANA DE DERECHOS HUMANOS. Informe Anual 2018, p. 86, 2019. Disponible en <http://www.corteidh.or.cr/tablas/informe2018/espanol.pdf>. Acceso en: 06 ago. 2019.

CONTESSE, Jorge. The International Authority of the Inter-American Court of Human Rights: A Critique of the Conventionality Control Doctrine. The International Journal of Human Rights, vol. 22, n. 9, dic. 2017.

COOPERATIVA.CL. Prensa argentina: Piñera pidió a Macri apoyar sus críticas a la CIDH. Cooperativa.CL, Abr. 24. Disponible en <https://www.cooperativa.cl/noticias/pais/relaciones-exteriores/ prensa-argentina-pinera-pidio-a-macri-apoyar-sus-criticas-a-la-cidh/2019-04-24/193120.htm>. Acceso en: 6 ago. 2019. 
COOPERATIVA.CL. Human Rights Watch: Gobierno de Piñera impulsó críticas internacionales a CIDH. Cooperativa.CL, Abr. 25. Disponible en <https://www.cooperativa.cl/noticias/pais/ relaciones-exteriores/human-rights-watch-gobierno-de-pinera-impulso-criticas-internacionales/2019-04-25/084313.html>. Acceso en: 6 ago. 2019.

DULITZKY, Ariel E. ¿An Inter-American Constitutional Court? The Invention of the Conventionality Control by the Inter-American Court of Human Rights. Texas International Law Journal, vol. 50, n. 1, p. 45-94, 2015.

FERRER MAC-GREGOR POISOT, Eduardo. El Control de Convencionalidad en la Jurisprudencia de la Corte Interamericana de Derechos Humanos (A Una Década de su Creación: 2006-2016). En: HENRÍQUEZ VIÑAS, Miriam; MORALES ANTONIAZZI, Mariela. El Control de Convencionalidad: Un Balance Comparado a 10 Años de Almonacid Arellano vs. Chile, Ediciones Der, Santiago, p. 37-69, 2017.

FIKFAK, Veronika. Changing State Behaviour: Damages before the European Court of Human Rights. The European Journal of International Law, vol. 29, n. 4, p. 1091-1125, nov. 2018.

FUENTES TORRIJO, Ximena. International and Domestic Law: Definitely an Odd Couple. Revista Jurídica de la Universidad de Puerto Rico, vol. 77, p. 483-505, 2008.

FUENTES TORRIJO, Ximena. Una Nueva Constitución para Chile y el Diseño de un Esquema de Incorporación del Derecho Internacional al Sistema Jurídico Chileno. En: CHÍA, Eduardo A.; QUEZADA, Flavio (eds.). Propuestas para una Nueva Constitución (Originada en Democracia), Instituto Igualdad - Facultad de Derecho Universidad de Chile - Friedrich Ebert-Stiftung, Santiago, p. 174-175, 2015.

GOBIERNO NACIONAL DE PARAGUAY. Gobiernos de Argentina, Brasil, Chile, Colombia y Paraguay se Manifiestan sobre el Sistema Interamericano de Derechos Humanos. Gobierno Nacional de Paraguay, Asunción, Abr. 24, 2019. Disponible en <https://www.mre.gov.py/index.php/noticias-de-embajadas-y-consulados/gobiernos-de-argentina-brasil-chile-colombia-y-paraguay-se-manifiestan-sobre-el-sistema-interamericano-de-derechos-humanos>. Acceso en: 6 ago. 2019.

GONZÁLEZ DOMÍNGUEZ, Pablo. Reconfiguración de la relación entre el derecho internacional de los derechos humanos y el derecho nacional sobre la base del principio de subsidiariedad. Anuario Mexicano de Derecho International, vol. XVII, p. 717-748, dic. 2017.

HAWKINS, Darren; JACOBI, Wade, Partial Compliance: A Comparison of the European and Inter-American Courts for Human Rights. Journal of International Law and International Relations, vol. 6, n. 1, p. 35-85, 2010.

HIGH LEVEL CONFERENCE ON THE FUTURE OF THE EUROPEAN COURT OF HUMAN RIGHTS. Brighton Declaration, Abr. 2012. Disponible en <https://www.echr.coe.int/Documents/2012_Brighton_FinalDeclaration_ENG.pdf >. Acceso en: 26 jul. 2019., 
HIGH LEVEL CONFERENCE MEETING IN COPENHAGEN. Copenhagen Declaration, Abr. 2018. Disponible en <https://www.echr.coe.int/Documents/Copenhagen_Declaration_ENG.pdf >. Acceso en: 26 jul. 2019.

MADRAZO LAJOUS, Alejandro et al. Posicionamiento frente a la Declaración sobre el Sistema Interamericano de Derechos Humanos, Ciudad de México, May. 9, 2019. Disponible en <https:// ibero.mx/files/2019/posicionamiento_cidh_ibero_osidh.pdf>. Acceso en: 6 ago. 2019.

MASERI, Sergio Gómez. HRW denuncia ataque de Colombia y otros países contra la CIDH. EI Tiempo, Washington, Abr. 24. Disponible en <https://www.eltiempo.com/mundo/eeuu-y-canada/denuncian-ataque-de-colombia-y-otros-paises-contra-la-cidh-353034>. Acceso en: 6 ago. 2019.

NASH ROJAS, Claudio. La Doctrina del Margen de Apreciación y su Nula Recepción en la Jurisprudencia de la Corte Interamericana de Derechos Humanos. ACDI-Anuario Colombiano de Derecho Internacional, vol. 11, p. 71-100, 2018.

NIKKEN, Pedro. El Sedicente 'Fortalecimiento' del Sistema Interamericano de Derechos Humanos y sus Dobles Estándares Frente a las Obligaciones Internacionales de los Estados Americanos. Revista Instituto Interamericano de Derechos Humanos, vol. 56, p. 76-80, jul.-dic. 2012.

NOGUEIRA ALCALÁ, Humberto. Los Desafíos del Control de Convencionalidad del Corpus luris Interamericano para las Jurisdicciones Nacionales. Boletín Mexicano de Derecho Comparado, vol. Año XLV, n. 135, p. 1167-1220, sep.-dic. 2012.

NÚÑEZ POBLETE, Manuel. Sobre la Doctrina del Margen de Apreciación Nacional. La Experiencia Latinoamericana Confrontada y el Thelos Constitucional de una Técnica de Adjudicación del Derecho Internacional de los Derechos Humanos. En: NÚÑEZ POBLETE, Manuel; ACOSTA ALVARADO, Paola Andrea (eds.). El Margen de Apreciación en el Sistema Interamericano de Derechos Humanos: Proyecciones Regionales y Nacionales, Universidad Nacional Autónoma de México. Instituto de Investigaciones Jurídicas, México, p. 3-49, 2012.

PASQUALUCCI, Jo M. The Practice and Procedure of the Inter-American Court of Human Rights, 2. ed., Cambridge University Press, New York, 2014.

PAÚL, Álvaro. Admissibility of Evidence before the Inter-American Court of Human Rights, Revista Direito GV, vol. 13, n. 2, p. 663-673, mai-ago 2017.

PAÚL, Álvaro. Elementos para Reinterpretar el Artículo 29 de la Convención Americana de Derechos Humanos. En: ACOSTA ALVARADO, Paola Andrea; DELPIANO LIRA, Cristián (eds.). América Latina y el Orden Mundial Contemporáneo, Universidad Externado de Colombia - Sociedad Latinoamericana de Derecho Internacional, Bogotá, p. 131-147, 2017.

PAÚL DÍAZ, Álvaro. La Corte Interamericana in Vitro: Comentarios sobre su Proceso de Toma de Decisiones a Propósito del Caso Artavia. Derecho Público Iberoamericano, vol. 2, p. 303-345, abr. 2013. 
PAÚl, Álvaro. The American Convention on Human Rights: Updated by the Inter-American Court. Juris Dictio, vol. 20, p. 53-86, dec. 2017.

PAÚL, Álvaro. The Emergence of a More Conventional Reading of the Conventionality Control Doctrine. Revue Générale de Droit, vol. 49, p. 275-302, feb. 2019.

PAÚL, Álvaro. The Inter-American Commission on Human Rights' Initial Review of Petitions, Its Backlog, and the Principle of Subsidiarity. The George Washington International Law Review, vol. 49, p. 19-52, feb. 2016.

SAGÜÉS, Néstor Pedro. Obligaciones Internacionales y Control del Convencionalidad. Estudios Constitucionales, vol. 8, n. 1, p. 117-136, 2010.

SILVA ABBOT, Max. Control de Convencionalidad Interno y Jueces Locales: Un Planteamiento Defectuoso. Estudios Constitucionales, vol. 14, n. 2, p. 101-141, jul. 2016.

TRIBUNAL EUROPEO DE DERECHOS HUMANOS. Caso Lautsi y otros vs. Italia, Acción n 30814/06. Publicado en 18 mar. 2011.

TRIBUNAL EUROPEO DE DERECHOS HUMANOS. Caso Leyla Şahin vs. Turquía, Acción n 44774/98. Publicado en 10 nov. 2005.

TUCKER, Duncan. Américas. Sistema Interamericano constituye una garantía fundamental para la vigencia de los derechos humanos en la región. Amnistía Internacional, Abr. 24. Disponible en <https://www.amnesty.org/es/latest/news/2019/04/americas-sistema-interamericano-fundamental-para-derechos-humanos/>. Acceso en: 17 sep. 2019. 